\title{
Neurocysticercosis: a contemporary presentation of the neuroimaging main stages
}

\author{
Mariana Lopes (ㄷ), Mafalda Ferreira 다, 2,3 Isabel Ramos, ${ }^{1,3}$ Pedro Melo Freitas ${ }^{4}$
}

${ }^{1}$ Department of Infectious

Diseases, Centro Hospitalar e Universitário de Coimbra EPE, Coimbra, Portugal

${ }^{2}$ Department of Internal Medicine, Centro Hospitalar e Universitário de Coimbra EPE, Coimbra, Portugal

${ }^{3}$ Faculty of Medicine, University of Coimbra, Coimbra, Portugal ${ }^{4}$ Neuroradiology Unit - Medical Imaging Department, Centro Hospitalar e Universitario de Coimbra EPE, Coimbra, Portugal

\section{Correspondence to} Dr Mariana Lopes; m.cardosolopes92@gmail.com

Accepted 11 January 2022

\section{DESCRIPTION}

Cysticercosis is a tissue infection caused by larval cysts of the tapeworm Taenia solium that is acquired from faecal-oral transmission (ingestion of eggs present in contaminated food or water) and is one of the major causes of epilepsy in areas where T. solium is endemic. ${ }^{12}$ Migration from endemic areas is one of the reasons why Portugal is the second country in Western Europe with a higher number of human cysticercosis hospitalisation cases with a mean of 45 cases per year. ${ }^{34}$

Diagnosis of neurocysticercosis is based on exposure history and neuroimaging and confirmed by serological testing, but neuroimaging might be enough to establish the diagnosis if there is evidence of a scolex on a cystic lesion or a combination of parasite cysts in different stages. ${ }^{125}$

We report a case of a young man of African origin, resident in Portugal for several months, without relevant medical history. The prehospital emergency team was activated due to an episode of generalised tonic-clonic seizure, witnessed by his girlfriend. At arrival, the patient presented psychotic symptoms involving persecutory delusions and aggressiveness.

On admission to the emergency department, he underwent a head CT that showed several cystic lesions suggestive of parasitic origin at different stages (figure 1). Electroencephalogram showed no epileptic activity or focal changes. At hospital admission, the patient was calm, with an unremarkable physical examination.

After admission to the infectious diseases ward, head MRI was performed which confirmed
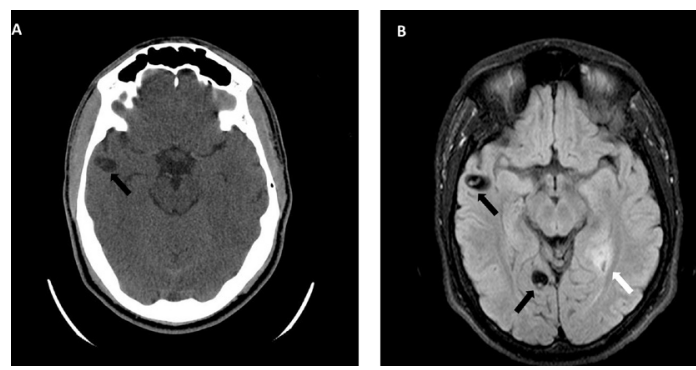

Figure 1 Non-contrast axial CT image (A) showing a cyst in the vesicular stage in the right temporal lobe (dark arrow). Axial FLAIR (B) shows three cystic lesions, two in the vesicular stage, with identifiable intracystic scolex (dark arrows) and one in a granular-nodular stage with cyst retraction (white arrow). FLAIR - Fluid-attenuated inversion recovery
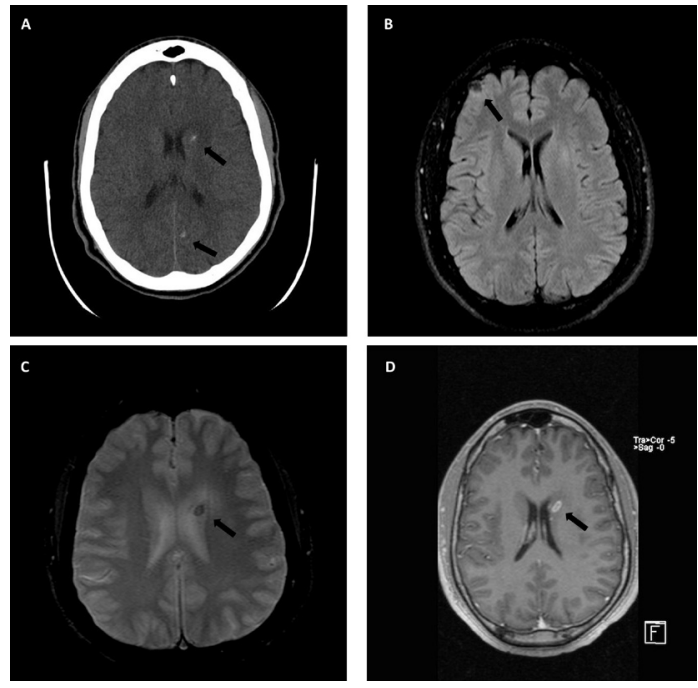

Figure 2 Non-contrast axial CT image (A) showing two nodular calcified stage cysticercosis lesions (dark arrows). Axial FLAIR (B) of a cyst on the early colloidal-vesicular stage in the right frontal lobe with vasogenic oedema surrounding the cyst (dark arrow). Axial T2-weighted (C) and axial postcontrast T1-weighted (D) sequences displaying a granular-nodular lesion (dark arrow). FLAIR Fluid-attenuated inversion recovery

the diagnosis of parenchymal neurocysticercosis with multiple lesions in all stages of radiologic presentation. Cysts with prominent scolex were visible (figure 2). Funduscopic examination excluded ocular cysticercosis.

Three parasitological stool samples collected 1 day apart were negative. Anti-T. solium IgG antibodies were not detected by ELISA test and western-blot assay on sera was inconclusive.

In the first days of admission, symptomatic treatment with levetiracetam and dexamethasone was started. After the result of MRI, targeted therapy with albendazole and praziquantel was administered for 14 days.

The patient remained stable during hospitalisation, without further episodes of seizure or behavioural changes. MRI after completing therapy exhibited a reduction of lesions dimensions.

He was discharged and kept follow-up in infectious diseases appointments.

This case represents a classic presentation of neurocysticercosis with an uncommon feature of peri-ictal psychosis. Its most interesting feature is the richness of radiographic data, namely the presence of the four stages of parenchymal neurocysticercosis, known as Escobar's 
pathological stages. ${ }^{67}$ Calcifications are best visualised on non-contrast CT scan and more recent lesions on MRI. ${ }^{8}$ The presence of antibodies for T. solium by enzyme-linked immunotransfer blot is useful to confirm the diagnosis, although in this case, serological tests were negative. This possibility is described in the literature ${ }^{9}$ and does not rule out the diagnosis. If parenchymal cystic lesions are visible 6 months after treatment, retreatment is advisable. ${ }^{1}$

\section{Learning points}

Seizures are the most common clinical presentation of neurocysticercosis and less frequently behavioural changes or psychosis may be present and it is important to exclude this organic cause particularly if there is an exposure history compatible with cysticercosis.

- Complementarity of CT scan and MRI is extremely helpful and, if the scolex is identified, the diagnosis of neurocysticercosis is certain.

Contributors ML and MF elaborated the draft of the work; IR and PMF revised the draft critically for important intellectual content and made the final approval of the version to be published.

Funding The authors have not declared a specific grant for this research from any funding agency in the public, commercial or not-for-profit sectors.

Competing interests None declared.

Patient consent for publication Consent obtained directly from patient(s)

Provenance and peer review Not commissioned; externally peer reviewed.
Case reports provide a valuable learning resource for the scientific community and can indicate areas of interest for future research. They should not be used in isolation to guide treatment choices or public health policy.

\section{ORCID iDs}

Mariana Lopes http://orcid.org/0000-0002-4181-0830

Mafalda Ferreira http://orcid.org/0000-0002-7504-3385

\section{REFERENCES}

1 White AC, Coyle CM, Rajshekhar V, et al. Diagnosis and treatment of neurocysticercosis: 2017 clinical practice guidelines by the infectious diseases Society of America (IDSA) and the American Society of tropical medicine and hygiene (ASTMH). Am J Trop Med Hyg 2018;98:945-66.

2 Rodrigues A, Neves D, Maury I, et al. A classic neurocysticercosis case with an unusual complication. EJCRIM 2017;4

3 Fabiani S, Bruschi F. Neurocysticercosis in Europe: still a public health concern not only for imported cases. Acta Trop 2013;128:18-26.

4 Laranjo-González M, Devleesschauwer B, Trevisan C, et al. Epidemiology of taeniosis/ cysticercosis in Europe, a systematic review: Western Europe. Parasit Vectors 2017;10:349.

5 Carpio A, Fleury A, Romo ML, et al. New diagnostic criteria for neurocysticercosis: reliability and validity. Ann Neurol 2016;80:434-42.

6 Balraj D, Sumit J K, Naghme A. Imaging in neurocysticercosis. Pract Neurol 2014;0:1-4

7 Escobar A. The pathology of neurocysticercosis. In: Palacios E, Rodriguez-Carbajal J, Taveras JM, eds. Cysticercosis of central nervous system. Springfield: Charles C Thomas, 1983: 27-54.

8 Lerner A, Shiroishi MS, Zee C-S, et al. Imaging of neurocysticercosis. Neuroimaging Clin NAm 2012;22:659-76.

9 Tsang VC, Brand JA, Boyer AE. An enzyme-linked immunoelectrotransfer blot assay and glycoprotein antigens for diagnosing human cysticercosis (Taenia solium). $J$ Infect Dis 1989;159:50-9. Volume.

Copyright 2022 BMJ Publishing Group. All rights reserved. For permission to reuse any of this content visit

https://www.bmj.com/company/products-services/rights-and-licensing/permissions/

BMJ Case Report Fellows may re-use this article for personal use and teaching without any further permission.

Become a Fellow of BMJ Case Reports today and you can:

- Submit as many cases as you like

- Enjoy fast sympathetic peer review and rapid publication of accepted articles

- Access all the published articles

- Re-use any of the published material for personal use and teaching without further permission

Customer Service

If you have any further queries about your subscription, please contact our customer services team on +44 (0) 2071111105 or via email at support@bmj.com.

Visit casereports.bmj.com for more articles like this and to become a Fellow 